Research Article,

\title{
Predictor Associated with Unmet Need for Family Planning among Saudi Postpartum Women: Mind the Gap.
}

\author{
Samaher Mohammed Al Mohaisen', Amen Bawazir ${ }^{2}$ \\ ${ }^{1}$ Ministry of Health, Primary health care Department. Riyadh, Saudi Arabia.
}

${ }^{2}$ Community and Environmental Health. College of Public Health and health Informatics, King Saud Bin Abdul-Aziz University for Health Sciences (KSAU-HS). King Abdullah International Medical Research

Center (KAIMRC)

Email Address:bawazir56@gmail.com

\begin{abstract}
Objective: This study aimed to explore the magnitude and related factors of the unmet need for postpartum family planning among Saudi women in Riyadh.

Methods: The cross-sectional survey was conducted in 2018 among postpartum women of less than 12 months. A structured questionnaire was used to collect the required data from 400 participants in primary health care (PHC) settings in Riyadh. Logistic regression model was used to determine the factors of unmet need.

Results: The proportion of unmet need for postpartum family planning among women was found to be $20.5 \%$. Around half $(55.8 \%)$ of the participants reported that they had used family planning methods in the past. About $62 \%$ of the participants reported using modern contraceptive methods. Women over 30 years were 3 times more likely to be pregnant without using contraceptives (AOR:3.17; CI: 1.55-6.50; p: 0.002). Women who have 3 or more kids were 2.51 times more likely to experience unwanted pregnancies than women with fewer kids (OR: 2.55, CI: 1.17-5.56, $\mathrm{p}=0.018$ ).

Conclusion: The unmet need for postpartum family planning is almost double the global average and neighbour countries. There is a need to educate women about the importance of contraceptives use in the kingdom.
\end{abstract}

Key words: Family planning; unmet need; Postpartum; Contraceptives.

\section{Introduction:}

\section{Background}

Unmet need is the gap between women's childbearing intentions and their contraceptive behavior, resulting in unintended or mistimed pregnancies [1-3]. Around 25\% of inter-birth spacing in developing countries is shorter than 24 months [4]. Premature births, low birth weight, infant mortality, and elevated maternal health risks, such as puerperal endometritis, anemia, rupture of membranes, and even death, are usually associated with closely spaced pregnancies[5 6].In 2017, there were 142 million married women with unmet need, according to the United Nations; however, the number is expected to decline to 139 million in 2030[7].

Postpartum family planning (PPFP) is a relatively recent field of academic interest, and after being neglected for a long time, PPFP is gaining momentum. A few studies surrounding PPFP have been carried out globally. Some of these studies have broadly investigated the issue, while others have chosen to focus on 
particular regions of the world, such as Africa, Asia, and the Middle East[8 9]. The East African countries seem to have the highest rates of PPFP (43\%), more than three times the global average. Women usually neglect or avoid FP after childbirth, which results in a higher unmet need for PPFP. In 2016, the unmet need for PPFP represented 65\% of all unmet needs in the Arab world [2].

In Saudi Arabia, studies have provided empirical data on the use of contraception in the cities of $\mathrm{Abha}, \mathrm{Al}$ Madinah, and Al Qassim Region [3 610 11]. In Aseer and Abha, only one study was performed exploring the unmet need in such a population[3]. These studies aimed to investigate Saudi women's reproductive behavior in the wake of new socio-demographic shifts in the region[3 61011 1]. They also suggested an unmet need for family planning; despite this change (FP).These findings offer insights into the unmet need for FP in some regions of the kingdom. However, because of their regional scope, they do not represent unmet needs nationwide [3 6 10].

Research on other regions of the country must be carried out to get an adequate understanding of the phenomenon, and this is where the scope of this research falls. Riyadh city offers a fertile ground for the study of unmet need because it is the capital and one of the country's biggest cities, which will increase the reliability of the findings. Moreover, the above-mentioned studies in Saudi Arabia focused on FP in general, whether to space pregnancies or to stop giving birth[3 10 11]. Since postpartum pregnancies bring a high health risk for both mother and child, it is necessary to assess the burden of unmet need of postpartum family planning in Saudi Arabia to address their need. Thus, the objective of this study was to measure the magnitude and factors of the unmet need for PPFP in Riyadh, Saudi Arabia.

\section{Material and Methods:}

\section{Study design and setting}

To measure the rate of unmet need for PPFP, we conducted a cross-sectional descriptive study in Riyadh, which is Saudi Arabia's second biggest city in terms of demographic density. According to the 2016 demographic survey, Riyadh topped in the age and sex distribution of the population with $37.6 \%$ of its population in the age group of 15-65 years and of this group 48\% are women. This is suitable for the research scope as most of the fecund and sexually active women are in this group. As this study used women attending primary health care (PHC) centers in Riyadh city, these centers were the framework of our sample. A round of 95 PHC centers distributed in five main regions (South, North, Central, East, and West).

\section{Sampling and Study Population}

The study included all postpartum Saudi women aged between 15- and 49-yearsold living in Riyadh who had given birth in the last 12 months prior to the study. Women who did not provide written informed consent were excluded from the study. Based on the sample size assumption, we required a minimum of 400 participants to conduct the study. We used a simple random sampling method to select the study participants. The sample size in each primary health care was based on the percentages of the PHC in each region strata. For the sake of consistency, only 2 centers have been selected for each region, making 10 of the total number of health centers surveyed.

\section{Primary Outcome variable}

The primary Outcome variable was an unmet need for postpartum family planning, and it was defined as women who perceived themselves as not being fecund (even though they are physiologically fecund) either because they don't have sex frequently or those who, after six months postpartum, still think they are amenorrhoeic, and women who don't want to become pregnant, who think they are at risk of pregnancy and yet don't use any contraceptive method.

On the other hand, met need for postpartum family planning was defined as women who were currently on a modern contraceptive plan, and women who used traditional contraception method and believe that their need is met.

\section{Independent variables}

The dependent variables were regressed against several socio-demographic variables. These included participant's age at the time of the survey and marriage, place of living (city or countryside), occupation 
(housewife or working), mother's education, income level (enough/not enough), number of living children, and number of sons and history of wanted pregnancy (Yes/No).

\section{Data collection and study measures}

The data were collected between August $1^{\text {st }}$ and October $1^{\text {st }}$, 2018. A validated questionnaire was used and self-administered for the randomly enrolled women who met the inclusion criteria. The questionnaire was translated into Arabic to make it accessible to all women in the health centers. Apilot study was conducted to check the questionnaire's validityon 20 women $(5 \%)$ in settings other than study areas.

\section{Statistical Analysis}

Data were analyzed using SPSS version 25 . We calculated descriptive statistics in numbers, percentage, mean, standard deviation or median and range whenever appropriate. We used t-test, Chi-squared/Fisher's exact tests compare the groups for various continuous and categorical variables, respectively. Univariable analysis was done to identify the factors associated with unmet need and crude odds ratio with $95 \%$ confidence intervals were calculated. Univariable analysis was followed by multicollinearity assessment. This was followed by multivariable analysis by the purposeful selection method. Each independent variable's significance was assessed by its p-value of less than 0.05 and likelihood ratio testing. Confounding was assessed by change in estimate of coefficient by 15 percent.

\section{$\underline{\text { Results }}$}

\section{Socio-demographic characteristics of the participants}

Atotal of 400 women were studied. The mean age for the participants was 30.6 years ( \pm SD: 6 years) and the mean age at the time of marriage was 22.1 years. The total unmet need for postpartum family planning was 20.5\%.All the participants were from Riyadh, and none of the participants came from a rural background (Table 1).

Table 1 Socio-demographic characteristics of the participants $(n=400)$

\begin{tabular}{|l|l|c|c|}
\hline \multicolumn{2}{|l|}{ Characteristics } & n & \% \\
\hline \multirow{5}{*}{ Age groups (years) } & $\leq 25$ & 70 & 17.5 \\
\cline { 2 - 4 } & $25-29$ & 128 & 32.0 \\
\cline { 2 - 4 } & $30-34$ & 77 & 19.3 \\
\cline { 2 - 4 } & $35-39$ & 100 & 25.0 \\
\cline { 2 - 4 } & $\geq 40$ & 25 & 6.3 \\
\hline \multirow{5}{*}{ Age at marriage (years) } & $17-19$ & 90 & 22.5 \\
\cline { 2 - 4 } & $20-22$ & 144 & 36.0 \\
\cline { 2 - 4 } & $23-25$ & 110 & 27.5 \\
\cline { 2 - 4 } & $\geq 26$ & 56 & 14.0 \\
\hline Occupation & Housewife & 233 & 58.3 \\
\cline { 2 - 4 } & Working & 167 & 41.8 \\
\hline \multirow{5}{*}{ Mother education } & Basic education and below & 30 & 7.5 \\
\cline { 2 - 4 } & Secondary & 142 & 35.5 \\
\cline { 2 - 4 } & Diploma & 110 & 27.5 \\
\cline { 2 - 4 } & University & 118 & 29.5 \\
\hline Husband education & Basic education and below & 59 & 14.8 \\
\cline { 2 - 4 } & Secondary & 199 & 49.8 \\
\cline { 2 - 4 } & Diploma & 86 & 21.5 \\
\cline { 2 - 4 } & University & 56 & 14.0 \\
\hline Level of income & Good & 369 & 92.2 \\
\hline & Poor & 31 & 7.8 \\
\hline
\end{tabular}

\section{Fertility and reproductive characteristics}

Table 2 is shown that most of the mothers reported having 3 to 4 children (40.3\%). Having male children is significant in understanding unmet need. Almost high percentage of participants expressed wanted pregnancy $(83.8 \%)$. Only $16.3 \%$ of the women had previous unwanted pregnancies. Around half $(54.7 \%)$ of 
the pregnant women reported that this pregnancy was wanted. A high percentage $(74.7 \%)$ expressed their desire to have another child. Only $25.3 \%$ expressed their desire to limit pregnancies.

When asking the participants about the status of contraception use, almost high percentage (82, 9\%) answered they are already on a contraceptive, while around half $(55.8 \%)$ of them reported that they have had experienced the use of family planning in the past. Pills are the most used form of modern contraception with $51.2 \%$ use. Among the other modern contraceptives, hormonal methods, male condoms, and vaginal ring were the least used at 4.1 and $5.7 \%$ respectively (Figure 1).

Table 2: Fertility and reproductive characteristics of the participants $(n=400)$

\begin{tabular}{|c|c|c|c|}
\hline \multicolumn{2}{|l|}{ Characteristics } & $\mathrm{n}$ & $\%$ \\
\hline \multirow[t]{3}{*}{ Living Children } & $1-2$ & 153 & 38.3 \\
\hline & $3-4$ & 161 & 40.3 \\
\hline & $\geq 5$ & 86 & 21.5 \\
\hline \multirow[t]{4}{*}{ Number of male children } & 0 & 52 & 13.0 \\
\hline & 1 & 123 & 30.8 \\
\hline & 2 & 106 & 26.5 \\
\hline & $\geq 3$ & 119 & 29.8 \\
\hline \multirow[t]{2}{*}{ History of dead child } & Yes & 36 & 9.0 \\
\hline & No & 364 & 91.0 \\
\hline \multirow{2}{*}{ Unwanted pregnancy in the past } & Yes & 65 & 16.3 \\
\hline & No & 335 & 83.8 \\
\hline \multirow[t]{2}{*}{ Pregnancy status } & Currently pregnant & 95 & 23.8 \\
\hline & Not pregnant & 305 & 76.3 \\
\hline \multirow[t]{5}{*}{ Current Pregnancy in months } & 2 & 4 & 1.0 \\
\hline & 3 & 20 & 5.0 \\
\hline & 4 & 23 & 5.8 \\
\hline & 5 & 27 & 6.8 \\
\hline & 6 & 21 & 5.3 \\
\hline \multirow[t]{2}{*}{ Pregnancy Intention } & Yes & 52 & 54.7 \\
\hline & No & 43 & 45.3 \\
\hline \multirow[t]{2}{*}{ Want another child or stop } & Another child after a while & 71 & 74.7 \\
\hline & To stop having children forever & 24 & 25.3 \\
\hline \multirow[t]{2}{*}{ Are you still menstruating } & Yes & 291 & 95.4 \\
\hline & No & 14 & 4.6 \\
\hline \multirow[t]{2}{*}{ Currently used family planning methods } & Yes & 252 & 82,9 \\
\hline & No & 52 & 17.1 \\
\hline \multirow[t]{2}{*}{ Used family planning method in the past? } & Yes & 223 & 55.8 \\
\hline & No & 177 & 44,3 \\
\hline \multirow[t]{3}{*}{ Usedcontraceptive/currently using? } & Modern & 248 & 78.0 \\
\hline & Traditional & 56 & 17.6 \\
\hline & Both & 14 & 4.4 \\
\hline \multirow[t]{5}{*}{ Which type of family planning is used? } & Pills & 205 & 64.5 \\
\hline & IUD & 35 & 11.0 \\
\hline & Hormonal * & 13 & 4.1 \\
\hline & Barriers ** & 18 & 5.7 \\
\hline & Natural*** & 47 & 14.8 \\
\hline \multirow[t]{2}{*}{ Reason for Using it } & Spacing & 259 & 86.9 \\
\hline & Stop giving birth forever & 39 & 13.1 \\
\hline
\end{tabular}

$*($ Injection + Implant + Patch $) ; * *($ Condom + Vaginal Ring $) ; * * *($ Coitus + calendar +breast feeding) 
Samaher Al Mohaisen et.al./Predictor Associated with Unmet Need for Family Planning Among Saudi Postpartum Women: Mind the Gap.

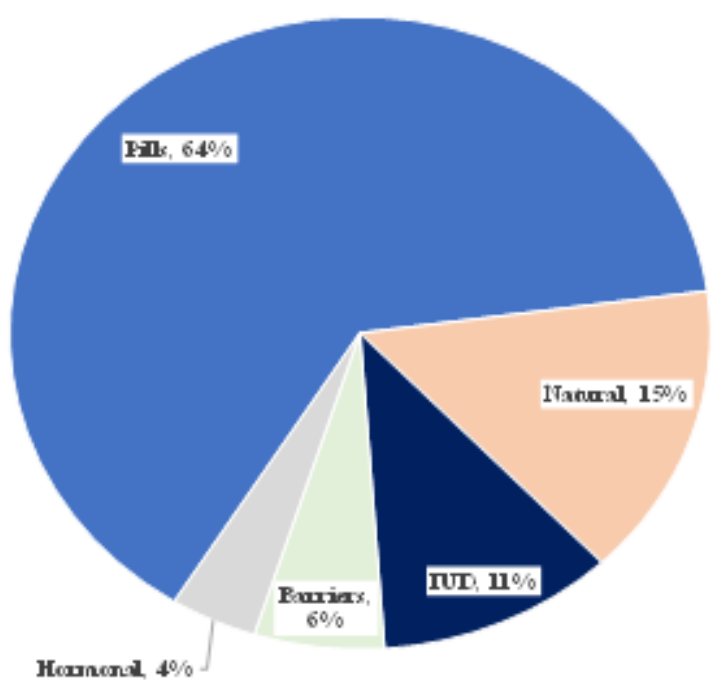

Figure 1 Prevalence of Contraceptive Use per Type

Table 3 Univariate and Multivariate Regression Analysis for Pregnancy Related factors (n=400)

\begin{tabular}{|c|c|c|c|c|c|c|c|}
\hline & & \multicolumn{3}{|c|}{ Univariate } & \multicolumn{3}{|c|}{ Multivariate } \\
\hline Factors & & OR & $95 \% \mathrm{CI}$ & P value & AOR & $95 \% \mathrm{CI}$ & $P$ value \\
\hline \multirow[t]{2}{*}{ Age groups } & $<30$ years & $\mathrm{R}$ & & & $\mathrm{R}$ & & \\
\hline & $\geq 30$ years $>$ & 2.000 & $0.898-4.457$ & 0.090 & 1.809 & $0.889-3.680$ & 0.102 \\
\hline \multicolumn{8}{|c|}{$\begin{array}{l}\text { Age at } \\
\text { (years) }\end{array}$ marry $<23$ years } \\
\hline & $\geq 23$ years & 0.851 & $0.442-1.641$ & 0.631 & & & \\
\hline \multirow{2}{*}{ Mother education } & $\leq$ Secondary & $\mathrm{R}$ & & & - & & \\
\hline & University & 0.924 & $0.469-1.819$ & 0.819 & & & \\
\hline \multirow[t]{2}{*}{ Husband education } & $\leq$ Secondary & $\mathrm{R}$ & & & & & \\
\hline & University & 1.082 & $0.572-2.048$ & 0.808 & & & \\
\hline \multirow[t]{2}{*}{ Occupation } & Housewife & $\mathrm{R}$ & & & $\mathrm{R}$ & & \\
\hline & Working & 0.516 & $0.258-1.030$ & 0.061 & 1.863 & $1.030-3.368$ & 0.039 \\
\hline \multirow[t]{3}{*}{ Total children } & $1-2$ children & 7.655 & $2.669-21.961$ & 0.000 & 8.916 & $3.409-23.320$ & 0.000 \\
\hline & 3-4 children & 2.537 & $1.198-5.373$ & 0.015 & 2.499 & $1.208-5.170$ & 0.014 \\
\hline & $\geq 5$ children & $\mathrm{R}$ & & & $\mathrm{R}$ & & \\
\hline \multirow{4}{*}{ Male child } & No male children & 1.383 & 0.434-4.404 & 0.583 & & & \\
\hline & 1 child & 1.424 & $.599-3.380$ & 0.424 & & & \\
\hline & 2 male children & 0.834 & $0.416-1.670$ & 0.608 & & & \\
\hline & $\geq 3$ male children & $\mathrm{R}$ & & & & & \\
\hline \multirow[t]{2}{*}{ Level of income } & Good & 1.125 & $0.403-3.143$ & 0.822 & & & \\
\hline & Poor & $\mathrm{R}$ & -1 & - & - & & \\
\hline
\end{tabular}


Samaher Al Mohaisen et.al./Predictor Associated with Unmet Need for Family Planning Among Saudi Postpartum Women: Mind the Gap.

Table 4 Univariate and Multivariate Regression Analysis for Factors on Contraceptive Use (n=400)

\begin{tabular}{|c|c|c|c|c|c|c|c|}
\hline & & \multicolumn{3}{|c|}{ Univariate } & \multicolumn{3}{|c|}{ Multivariate } \\
\hline \multirow{2}{*}{\begin{tabular}{|l} 
Factors \\
\end{tabular}} & & OR & $95 \% \mathrm{CI}$ & P value & AOR & \multicolumn{2}{|c|}{ 95\% CIP value } \\
\hline & $<30$ years & $\mathrm{R}$ & & & $\mathrm{R}$ & - & \\
\hline Age groups & $\geq 30$ years $>$ & 4.620 & $1.879-11.358$ & 0.001 & 3.169 & $1.545-6.500$ & 0.002 \\
\hline \multirow[t]{2}{*}{ Age at marry (years) } & $<23$ years & 1.316 & $0.590-2.933$ & 0.502 & & - & \\
\hline & $\geq 23$ years & $\mathrm{R}$ & - & & & - & \\
\hline \multirow[t]{2}{*}{ Mother education } & $\leq$ Secondary & 1.348 & $0.583-3.119$ & 0.485 & & - & \\
\hline & University & $\mathrm{R}$ & t- & & & - & \\
\hline \multirow[t]{2}{*}{ Husband education } & $\leq$ Secondary & 0.683 & $0.330-1.413$ & 0.304 & & - & \\
\hline & University & $\mathrm{R}$ & - & & & - & \\
\hline \multirow[t]{2}{*}{ Occupation } & Housewife & 1.634 & $0.687-3.888$ & 0.267 & & - & \\
\hline & Working & $\mathrm{R}$ & - & & & - & \\
\hline \multirow[t]{3}{*}{ Total children } & $1-2$ children & 1.553 & $0.504-4.784$ & 0.443 & & - & \\
\hline & 3-4 children & 2.692 & $0.955-7.589$ & 0.061 & & - & \\
\hline & $\geq 5$ children & $\mathrm{R}$ & - & & & - & \\
\hline \multirow[t]{4}{*}{ Male child } & No male children & 5.644 & $1.644-19.377$ & 0.006 & 3.735 & $1.272-10.963$ & 0.016 \\
\hline & 1 child & 3.505 & $1.166-10.539$ & 0.026 & 2.686 & $1.040-6.939$ & 0.041 \\
\hline & 2 male children & 3.586 & $1.320-9.746$ & 0.012 & 2.909 & $1.145-7.392$ & 0.025 \\
\hline & $\geq 3$ male children & $\mathrm{R}$ & - & & $\mathrm{R}$ & - & \\
\hline \multirow[t]{2}{*}{ Level of income } & Good & 0.431 & $0.130-1.436$ & 0.171 & & - & \\
\hline & Poor & $\mathrm{R}$ & - & & -1 & - & \\
\hline
\end{tabular}

$\mathrm{R}=$ reference

\section{Reasons for not using any means to prevent or regulate pregnancy}

The highest percentage of women reported that they were not on a contraceptive plan because they were either breastfeeding and/or because they did not have frequent sexual intercourse $(31.7 \%)$. The second-high percentage was assigned to reasons related to family issues $(30.5 \%)$. Health issues and reasons related to contraceptives scored the lowest at $3.7 \%$ and $6.1 \%$, respectively. $17 \%$ of the participants who reported not having been oncontraceptive plan lacked knowledge of contraception, and $11 \%$ avoided it for religious reasons.

\section{Univariate and Multivariate Regression Analysis}

A univariate and multivariate analysis was conducted to determine pregnancy-related factors. Among women who got married between the ages of 20-22, there was a higher chance of falling pregnant than those who got married 23-25 years old (OR: 3.894, CI: 1.30-11.61, p=0.015). Among those who have more than 2 male children, the likelihood of becoming pregnant were higher than those who have one male child (OR: 3.591, CI: $1.49-8.65, \mathrm{p}=0.001$ ), while those who have more than 5 children had a higher chance of falling pregnant than those who have 2-3 children (OR: 2.55, CI: 1.17-5.56, p=0.018). Similarly, findings were found with multivariate regression analysis for both factors, as shown in table 3 .

Another model was used for assessing factors affecting the probability of using contraception with sociodemographic variables. Women of age $\geq 30$ yearshave shown a higher chance of using contraceptives in comparison to those <30 years old (odds ratio [OR]: 4.62, confidence interval $[\mathrm{CI}]: 1.88-11.36, \mathrm{p}$ value $[\mathrm{p}]=0.001$ ). Also, women having no male child or only one male child were more likely to use contraceptives of five times and three times higher than for those with three male children respectively (OR: 5.64, CI: $1.64-19.38, \mathrm{p}=0.006$; $\mathrm{OR}=3.51,95 \% \mathrm{CI}=1.166-10.539$, and $\mathrm{p}=2.686$, respectively). Similarly, findings were found with multivariate regression analysis for both factors, as shown in table 4.

\section{Discussion:}

This study aimed to determine the level of unmet need for postpartum family planning (PPFP)and associated factors. The study found a rate of $20.5 \%$ of unmet need for PPFP among women in Riyadh city. Whileour findings were slightly lower than what was found at the national level, it is important to emphasize that this study is focused on PPFP and not on unmet needs in general. Two other studies conducted in the Southern Region of Saudi Arabia in general and in Abha and Asser in particular, of 34\% and 32.6\% of unmet need for 
family planning, respectively[3 12]. However, these two studies examined the women's contraceptive behavior up to 5 years prior to the time of their study. When comparing our findings to similar studies in the Arab world, the unmet need for PPFP in Saudi Arabia is higher than in Egypt (20.5\% versus 16.3\%) in 2017[5]. However, the estimated rate of unmet need in the Arab countries was found as 12\%, according to the last UN report (2017) on contraceptive prevalence [7].

Worldwide, the rates of unmet need for postpartum family planning vary significantly. Our findings are comparable to other studies conducted across the globe. For example, a group of researchers conducted a family planning study of six-week postpartum women in five low-income countries (2015): India, Zambia, Pakistan, Guatemala, and Kenya, they found that the unmet need for family planning ranged from $25.5 \%$ in Zambia to $96.6 \%$ in Pakistan [13]. Controversial findings were found between different studies conducted in the region. For example, a higher rate of unmet need for family planning was observed in Pakistan, Iraq, and Ethiopia than what we recorded in our study(32\%,28.1\%, 44\%, respectively)[14-16].

As to the prevalence of contraception use, this study has shown that $62 \%$ of women use modern contraceptive methods whereas $14 \%$ use traditional methods. It is noted here, that this level is higher than the national prevalence of unmet need which is $30 \%$ according to the UN report on contraceptive prevalence [7]. This level could vary between rural, semi-urban, and urban regions. All the study participants were from urban area. The educational level and the occupation of the participants explain the high prevalence of contraceptive use. When compared to other studies, the level of prevalence of contraceptive in this study is lower than prevalence from Al Madinah (88.0\%)[10], and Taif (67.7 \%) in Saudi Arabia, as well as in Egypt $(80.7 \%)$ [5 17]. However, it was higher than the prevalence reported in Abha and Asser, the southern part of the country $(54.7 \%)[3]$.

Postpartum family planning seeks to prevent closely spaced and unintended pregnancies in the first 12 months postpartum. Studies have revealed that $30 \%$ of maternal deaths and $10 \%$ of under-five child mortality can be prevented with the 2-years inter-birth interval[18].Preventing closely spaced and accidental pregnancies should target not only those women who indicated no use of family planning (perceived unmet need) but also those who don't automatically feel vulnerable to pregnancy (perceived no need) and those who use traditional FP methods (perceived met need). In this study, 14\% of FP's total need was met with traditional methods, and $2.8 \%$ do not see themselves at risk of falling pregnant.

Studies on unmet need for family planning usually distinguish four types of reasons: fear of side effects of the contraceptive methods, infrequent sex, opposition from partners and family members, and cultural and religious barriers [ $\left[\begin{array}{llll}9 & 15 & 19 & 20\end{array}\right]$. The WHO is intensifying its efforts to increase the prevalence of contraceptive use globally, with a focus on the least developed regions. The Family planning initiative of 2020 seeks to promote family planning to empower women in developing countries. This study has investigated the reasons for unmet need among the participants. The findings of the study reveal that breastfeeding and infrequent sex were the most reported reasons for unmet need, whereas family and health issues were the least reported reasons. The findings of the study concerning health issues are in contrast with many studies. In Egypt, fear of side effects were reported in 25\% of the participants [21] in 2018, and 19.2\% in postpartum women in 2017[5]. Family issues were strongly reported in this study, at 30.5\%. The issues involved the opposition of the husband and the opposition of the relatives. Much of the literature focuses on the role of the spouse in unmet need. Husband opposition appeared in 15.9\% of the cases in rural Egypt in 2018[21], and16.4\% in Iraq[14].

\section{Limitations of the study}

As this study was conducted in only one city of Saudi Arabia (Riyadh), the findings could not be generalized for the whole country and considered among the study's limitations. Anation-wide study is therefore needed to determine the real level of unmet need. The questionnaire used in the study addressed some critical areas of the unmet need, such as demographic characteristics, fertility preferences and contraceptive behavior. There are, however, a few variables that could have been included, such as the ideal number of children and the spouse's role in choosing family planning. These variables could have affected the level of unmet need. However, the current global trend is also using to measure unmet need by studying on men, as it usually investigates the attitudes and the collaboration of the husband in family planning. In this study, females were 
exclusively investigated. Therefore, a future study should be a male-based study to yield more results regarding the husband's opposition/permission to contraceptives.

While this study has some limitations, it is considered among the few studies conducted in Saudi Arabia and is the first to be conducted among attendees of the primary health care centers in the kingdom. Moreover, it is also the first study that investigates women in the postpartum state.

\section{Conclusion and recommendations}

Determining the level of unmet need for postpartum family planning has significant implications for policymakers. Unmet need for family planning is a burden to any government. It increases expenses in the health sector and hampers economic development. Meeting this need would have positive consequences forthe health sector in Saudi Arabia, and the national economy.

Based on the findings of this study, we suggest that contraceptive methods should be given free of charge at the level of public health centers to increase the rate of contraceptive use. Since family planningappliesto men and women, we would like to draw the attention of the Ministry of Health to the need to establish strategies for the unmet needs of both men and women. A suggestion can be made to the Ministry of Education to schedule health education programs for postpartum women to educate them about the use of modern contraception. We also recommend physicians and midwives in the public health centers speak to postpartum women about the use of family planning to encourage birth spacing.

\section{Abbreviations: \\ Postpartum family planning=PPFP}

Family planning=FP

Primary health care $=\mathrm{PHC}$

\section{Declaration}

Ethical approval: The study was approved by IRB Ethical Committee of King Abdullah International Medical Research Center (KAIMRC) at the Ministry of National Guard for Health Affairs (SP 18/070/R31). Additional IRB Ethical Approval from King Fahd Medical City (\#FWA00018774).

Consent for publication: not required.

Availability of data and materials: All cited articles are available online.

Competing interests: The authors declare that they have no competing interests.

Funding: Not applicable.

\section{References:}

[1] Kulczycki A. Overcoming family planning challenges in Africa: toward meeting unmet need and scaling up service delivery. African journal of reproductive health 2018;22(1):9-19. doi: http://doi:10.29063/ajrh2018/v22i1.1

[2] Cahill N, Sonneveldt E, Stover J, et al. Modern contraceptive use, unmet need, and demand satisfied among women of reproductive age who are married or in a union in the focus countries of the Family Planning 2020 initiative: a systematic analysis using the Family Planning Estimation Tool. The Lancet 2018;391(10123):870-82. doi: http://doi:10.1016/S0140-6736(17)33104-5

[3] Khalil SN, Alzahrani MM, Siddiqui AF. Unmet need and demand for family planning among married women of Abha, Aseer Region in Saudi Arabia. Middle east Fertility society journal 2018;23(1):31-36. doi: http://doi:10.1016/j.mefs.2017.07.004

[4] Wilopo SA, Setyawan A, Pinandari AW, et al. Levels, trends and correlates of unmet need for family planning among postpartum women in Indonesia: 2007-2015. BMC women's health 2017;17(1):120. doi: http://doi:10.1186/s12905-017-0476-x 
[5] Elweshahi HMT, Gewaifel GI, Sadek SSELD, et al. Unmet need for postpartum family planning in Alexandria, Egypt. Alexandria journal of medicine 2018;54(2):143-47. doi: http://doi:10.1016/j.ajme.2017.03.003

[6] Alharbi MM, Alharbi MS, Alnazzawi A, et al. Knowledge, attitudes and practices towards family planning among Saudi female teachers in Al-Madinah Al-Munawarah City, Saudi Arabia. Int J Acad Sci Res 2017;4:82-92. doi: http://doi:10.4103/jfmpc.jfmpc_363_18

[7] UN/DESA. World Family Planning 2017: Highlights. In.: United Nations, Department of Economic and Social Affairs, Population Division;: United Nations, 2017.

[8] Rossier C, Bradley SEK, Ross J, et al. Reassessing unmet need for family planning in the postpartum period. Studies in family planning 2015;46(4):355-67. doi: http://doi:10.1111/j.17284465.2015.00037.x.

[9] 9. Ali AAA, Okud A. Factors affecting unmet need for family planning in Eastern Sudan. BMC public health 2013;13(1):102. doi: http://doi:10.1186/1471-2458-13-102.

[10] 10. Habib HM, Aljohani AM, Sebeih SH, et al. Awareness of Antenatal Care importance among Saudi pregnant women in Madina. J Gynecol Women's Health 2017;4(4):555649. doi: http://doi:10.19080/JGWH.2017.04.555649.

[11] Al Sheeha M. Awareness and use of contraceptives among saudi women attending primary care centers in Al-qassim, saudi arabia. International journal of health sciences 2010;4(1):11.

[12] Roudi-Fahimi F, Monem AA, Ashford L, et al. Women's need for family planning in Arab countries. Population Reference Bureau 2012:1.

[13] Pasha O, Goudar SS, Patel A, et al. Postpartum contraceptive use and unmet need for family planning in five low-income countries. Reproductive health 2015;12(2):1-7. doi: http://doi:10.1186/1742-4755-12-S2-S11

[14] Al Ameen M, Dhia L. Unmet Need for Family Planning among Currently Married Women in Baghdad Al Karkh. 2016;29:223-29.

[15] Tegegn M, Arefaynie M, Tiruye TY. Unmet need for modern contraceptives and associated factors among women in the extended postpartum period in Dessie town, Ethiopia. Contraception and reproductive medicine 2017;2(1):21. doi: http://doi:10.1186/s40834-017-0048-3

[16] Anwar S, Aslam Z, Qureshi S, et al. Unmet Needs for Family Planning. Journal of Rawalpindi Medical College 2015;19(S-1):55-58

[17] Albezrah NA. Use of modern family planning methods among Saudi women in Taif, KSA. Int J Reprod Contraception Obstet Gynecol 2015;44:990-4. doi: http://dx.doi.org/10.18203/23201770.ijrcog20150412

[18] Adedini SA, Odimegwu C, Imasiku EN, et al. Unmet need for family planning: implication for under-five mortality in Nigeria. J Health Popul Nutr 2015;33(1):187-206.

[19] 19. John Cleland SH, and Iqbal H. Shah. Unmet Need for Contraception: Issues and Challenges. Studies in family planning 2014;45(2):105-22. doi: https://doi.org/10.1111/sifp.12056

[20] Bongaarts J. The Evolution of Family Planning Programs. Stud Fam Plann 2018 doi: https://doi.org/10.1111/sifp.12056

[21] El-Masry R, Essam N, Ghoneim M. Unmet need for family planning among women in rural Egypt. International Journal of Community Medicine and Public Health 2018;5(4):1252. doi: http://dx.doi.org/10.18203/2394-6040.ijcmph20181199 